\title{
Microtubule-associated Protein 1b (MAP1b) Is Concentrated in the Distal Region of Growing Axons
}

\author{
Mark M. Black, ${ }^{1}$ Theresa Slaughter, ${ }^{1}$ and Itzhak Fischer ${ }^{2}$ \\ ${ }^{1}$ Department of Anatomy and Cell Biology, Temple University School of Medicine, Philadelphia, Pennsylvania 19140 and \\ Department of Anatomy and Neurobiology, Medical College of Pennsylvania, Philadelphia, Pennsylvania 19129
}

Microtubule-associated protein 1b (MAP 1b) is expressed at especially high levels in neurons actively extending axons, and although it appears to be required for axon growth, the nature of its role is unknown. We reasoned that a detailed description of the localization of MAP1b in growing axons would help define how MAP1b participates in axon growth. Therefore, we have stained cultured sympathetic neurons with various antibodies against MAP $1 b$, and then used digital image processing and analysis procedures to quantify MAP $1 \mathrm{~b}$ distribution, phosphorylation and association with microtubules (MTs) in actively elongating axons. MAP1b is present on MTs all along the axon. Quantitative analyses showed that MAP 1b has a nonuniform distribution along growing axons. It is present at relatively low and constant levels along the axon shaft until $\approx \mathbf{1 3 0} \mu \mathrm{m}$ from the axon tip, where the amount of MAP1b begins to increase sharply and reaches a peak close to the growth cone. The peak amount of MAP 1b in the distal axon is an order of magnitude greater than the average amount in the axon shaft. The enrichment of MAP1b in the distal axon was observed for total MAP1b and assembled MAP 1b, and was even more pronounced for phosphorylated MAP1b. This distribution pattern remains after correcting the relative amount of MAP $1 b$ along the axon for variations in axonal volume. Thus, the concentration of MAP1b in the distal axon exceeds by severalfold that in the rest of the axon. The amount of assembled MAP $1 \mathrm{~b}$ relative to the amount of MT polymer also varies along the axon, and is greatest distally near the growth cone. This pattern of MAP1b localization in axons focuses attention on the distal axon and growth cone as the principal sites of MAP1b function in axon growth. We discuss the possibility that MAP 1b regulates $M T$ dynamics in the distal axon so that it is properly coordinated with growth cone events involved in axon extension.

[Key words: microtubules, microtubule-associated protein $1 \mathrm{~b}$, growth cone, axon growth, quantitative digital image processing, cultured sympathetic neurons]

Received May 25, 1993; revised July 29, 1993; accepted July 29, 1993.

This work was supported by NIH Grants NS17681 (M.M.B) and NS24275 and NS24707 (I.F.).

Correspondence should be addressed to Dr. Mark M. Black, Department of Anatomy and Cell Biology, Temple University School of Medicine, 3400 North Broad Street, Philadelphia, PA 19140.

Copyright (C) 1994 Society for Neuroscience $0270-6474 / 94 / 140857-14 \$ 05.00 / 0$
$\mathrm{M} \Lambda \mathrm{P} 1 \mathrm{~b}$ is a developmentally regulated microtubule (MT) protein that is especially prominent in neurons that are actively extending axons (Calvert and Anderton, 1985; Riederer et al., 1986; Garner et al., 1990; Fischer and Romano-Clarke, 1991). MAPlb is also relatively abundant in adult brain regions that continue to generate neurons (Safaei and Fischer, 1989; Viereck et al., 1989; Tucker, 1990). In PC12 cells stimulated by NGF treatment to extend axons, both MAP1b levels and its phosphorylation increase (Greene et al., 1983; Drubin et al., 1985; Aletta et al., 1988; Brugg and Matus, 1988). An increase in MAPlb phosphorylation also occurs during brain development, and appears to correlate with axon growth (Calvert et al., 1987; Sato-Yoshitake et al., 1989; Fischer and Romano-Clarke, 1990). These observations have led to the proposal that MAP1b has a role in axonal growth and that this function can be modulated by phosphorylation (Tucker, 1990; Diaz-Nido et al., 1991; Gordon-Weeks, 1991). Direct evidence for a role of MAP1b in axon growth has been provided by recent experiments showing that suppression of MAP $1 \mathrm{~b}$ expression by antisense oligonucleotide treatment also suppresses NGF-induced neurite outgrowth by PC1 2 cells (Brugg et al., 1993). While a role for MAP1 $b$ in axon elongation is now apparent, the nature of this role is unknown. Immunofluorescence and biochemical studies have shown that MAPlb is present in growing axons (Calvert and Anderton, 1985; Peng et al., 1986; Garner et al., 1990; Fischer and Romano-Clarke, 1991), and that some of the axonal MAPlb is associated with MTs (Peng et al., 1985; Reiderer et al., 1986). There are also suggestions of an enrichment of MAPIb in the distal part of growing axons, especially in the region of the growth cone (Fischer and Romano-Clarke, 1991; Mansfield et al., 1991). However, these latter studies did not reveal whether this is a true enrichment, or merely reflects the fact that growing axons are commonly greater in caliber distally compared to the axon shaft.

We reasoned that a more detailed description of the localization of MAPIb in growing axons together with an analysis of its association with MTs along the axon could help focus future experiments on the function of MAPlb in axon growth. In the present studies, we have used digital image processing procedures to quantify several aspects of MAP1 b localization in growing axons. Our studies show that MAP1b is highly enriched in the distal part of growing axons, and this is apparent even after correction for regional variations in axon volume. Furthermore, this enrichment is reflected in the assembled pool of MAPIb; MTs in the distal part of the axon contain severalfold more MAPlb than MTs of the axon shaft. These results focus atten- 
tion on the distal part of the axon as a primary site for the involvement of MAP1b in axon growth.

\section{Materials and Methods}

Cell culture. Rat sympathetic neurons were dissociated from the superior cervical ganglia of newborn pups as described by Black and Kurdyla (1983) and then plated onto glass coverslips coated with polylysine and laminin as described in Brown et al. (1992). All of the studies presented here were performed on cultures that varied between 17 and $25 \mathrm{hr}$ in age from the time of plating. By this time, most of the neurons had extended one or more axons and no dendrites.

Antibodies. We used the following antibodies in the present studies. A monoclonal antibody against $\beta$-tubulin was purchased from Amersham Corporation (Arlington Heights, IL; Blose et al., 1984). A polyclonal antibody against tyrosinated $\alpha$-tubulin was generously provided by Dr. Chloe Bulinski (Columbia University, New York, NY). A polyclonal antibody against MAP1b was prepared against a fusion protein containing $\approx 280$ amino acids from the middle of the MAP $1 \mathrm{~b}$ molecule; this antibody recognizes all isoforms of MAP1b (Safaei and Fischer, 1989). A monoclonal antibody was used, designated 1B-P, that recognizes a phosphorylation-dependent epitope of MAPlb (Boyne et al., 1992; Nothias et al., 1992). All secondary antibodies were purchased from Jackson Immunoresearch Laboratories, Inc., West Grove, PA (AffiniPure grade, preadsorbed for minimum cross-reactivity), and were reconstituted according to manufacturer instructions.

Immunofluorescence procedures. Neurons were processed for immunofluorescence according to one of two procedures. For procedure 1 , cells were rinsed once with PBS, once with PHEM 60 mM PIPES, 25 mм HEPES, 10 mм EGTA, 2 mm $\mathrm{MgCl}_{2}$. pH 6.9; Schliwa and van Blerkom, 1981), and then simultaneously fixed and extracted by incubation with PHEM containing 0.5\% Triton X-100 (Sigma), $2.0 \%$ paraformaldehyde (EM Sciences), and $0.05 \%$ glutaraldehyde (Polysciences) for $10 \mathrm{~min}$. For procedure 2, cells were extracted prior to fixation using conditions that stabilize existing MTs and remove unassembled tubulin. Neurons were rinsed once with PBS, once with PHEM, and then extracted at room temperature for $2 \mathrm{~min}$ in PHEM containing $0.2 \%$ saponin (Sigma Chemical Co., St. Louis, MO, prepared from Gypsophila sp.), and $10 \mu \mathrm{M}$ taxol (a gift from Ms. Nancita Lomax of the National Cancer Institute). The taxol was made as a $10 \mathrm{~mm}$ stock solution in dimethyl sulfoxide (Sigma), and appropriate volumes were added to the extraction buffer immediately prior to use. The extraction solution also contained a mixture of protease inhibitors $(0.2$ trypsin inhibitory units/ $\mathrm{ml}$ of aprotinin, and $10 \mu \mathrm{g} / \mathrm{ml}$ each of leupeptin, chymostatin, and antipain). After extraction, the cells were fixed by incubation with PHEM containing $2.0 \%$ paraformaldehyde and $0.05 \%$ glutaraldehyde for 10 min as described by Brown et al. (1992). Both of these procedures result in excellent morphological preservation. Procedure 1 results in minimal extraction of cell protein prior to fixation, whereas procedure 2 results in extraction of considerable cell protein, including unassembled tubulin (see Results and Fig. 4). For some experiments, cells were extracted in the presence of calcium to destabilize MTs. For these experiments, the extraction solution consisted of $60 \mathrm{~mm}$ PIPES, $25 \mathrm{~mm}$ HEPES, $1 \mathrm{~mm}$ $\mathrm{CaCl}_{2}, 2 \mathrm{mM} \mathrm{MgCl}_{2} \mathrm{pH} 6.9$, and contained $0.2 \%$ saponin, protease inhibitors, and no taxol.

After fixation by procedure 1 or 2, cells were rinsed with PBS and then incubated with $1 \%$ Triton X-100 in PBS for $15 \mathrm{~min}$. Subsequently, the dishes were rinsed with PBS, treated with three 5 min changes of sodium borohydride (Sigma; $10 \mathrm{mg} / \mathrm{ml}$ in a $1: 1$ mixture of PBS and methanol), rinsed with PBS again, and then incubated with blocking solution. Blocking solution consisted of either $4 \%$ normal goat serum or a mixture of $2 \%$ normal goat serum and $2 \%$ normal donkey serum in PBS. The cells were then double stained using one of four different combinations of antibodies against MAP $1 \mathrm{~b}$ and $\beta$-tubulin (see below). All antibodies were diluted in blocking solution and then clarified prior to use by centrifugation at $200,000 \times g$ for $10 \mathrm{~min}$ in a Beckman TL100 ultracentrifuge (Beckman Instruments Inc., Palo Alto, CA). After incubation with secondary antibody, cells were rinsed extensively with PBS and then mounted in $50 \%(\mathrm{w} / \mathrm{v})$ glycerol containing $10 \mathrm{mg} / \mathrm{ml}$ $n$-propyl gallate (Sigma)

The four staining conditions were as follows. In condition 1, cells were incubated first with a mouse monoclonal anti- $\beta$-tubulin antibody for $45 \mathrm{~min}$ at $37^{\circ} \mathrm{C}$, rinsed twice with blocking solution, and then incubated at $4^{\circ} \mathrm{C}$ overnight with a rabbit polyclonal anti-M $A \mathrm{P} 1 \mathrm{~b}$ antibody at $4^{\circ} \mathrm{C}$. The cells were then incubated simultaneously with fluorescein isothiocyanate (FITC)-conjugated goat anti-mouse antibody, at a dilution of 1:100, and Texas red-conjugated donkey anti-rabbit antibody, at a dilution of 1:400. In condition 2, cells were first incubated overnight at $4^{\circ} \mathrm{C}$ with a mouse monoclonal IgM antibody against a phosphorylation-dependent epitope of MAPlb (antibody 1B-P), rinsed twice with blocking solution, and then incubated for $45 \mathrm{~min}$ at $37^{\circ} \mathrm{C}$ with a rabbit polyclonal antibody specific for tyrosinated $\alpha$-tubulin. The cells were then incubated simultaneously with FITC-conjugated donkey anti-rabbit antibody, at a dilution of 1:100, and Texas red-conjugated goat antimouse antibody, IgM specific, at a dilution of 1:400. In condition 3, cells were incubated with the rabbit polyclonal antibody against MAPIb for 45 min at $37^{\circ} \mathrm{C}$, rinsed extensively with PBS, incubated with FITCconjugated donkey anti-rabbit antibody, at a dilution of $1: 100$, and then rinsed extensively with PBS. The cells were then reblocked; incubated overnight at $4^{\circ} \mathrm{C}$ with $1 \mathrm{~B}-\mathrm{P}$, the mouse monoclonal IgM antibody against a phosphorylation-dependent epitope of MAPlb; rinsed extensively with PBS; and then incubated with Texas red-conjugated goat anti-mouse antibudy, IgM specific, at a dilution of 1:600. In condition 4, cells were incubated first with the mouse anti- $\beta$-tubulin antibody for $45 \mathrm{~min}$ at $37^{\circ} \mathrm{C}$, rinsed twice with blocking solution, and then incubated overnight at $4^{\circ} \mathrm{C}$ with the $1 \mathrm{~B}-\mathrm{P}$ antibody. We distinguished these two mouse primary antibodies by taking advantage of the fact that the former is an $\mathrm{IgG}$, while the latter is an IgM. Thus, the cells were incubated simultaneously with FITC-conjugated goat anti-mouse antibody, IgG specific at a dilution of 1:100, and Texas red-conjugated goat anti-mouse antibody, $\operatorname{IgM}$ specific, at a dilution of 1:600. Control experiments estahlished that the second antibodies had appropriate specificity for mouse immunoglobins of either the IgG or IgM class (data not shown).

For some experiments, the rabbit polyclonal antibody against MAP $1 \mathrm{~b}$ was preincubated with MAPs prepared from the brains of newborn rat pups. MTs were assembled from a high-speed supernatant of the brains using taxol, and then the MAPs were isolated from the MTs using $\mathrm{NaCl}$ extraction (Vallee, 1982; Peng et al., 1985). For preadsorption experiments, the polyclonal antibody was incubated with either the MAP preparation or the $\mathrm{NaCl}$-containing buffer used to extract MAPs from MTs for $15 \mathrm{~min}$ at room temperature, clarified by centrifugation, and then used for immunostaining as described above.

Imaging. Cells were observed by differential interference contrast (DIC) or epifluorescence microscopy using a Zeiss Axiovert 35 inverted microscope (Carl Zeiss, Inc., Thornwood, NY). For epifluorescence microscopy, the cells were illuminated with a $100 \mathrm{~W}$ mercury arc lamp and observed using fluorescein (Zeiss filter set \#10) and rhodamine (Zeiss filter set \#14) filter sets. A heat-absorbing colored glass filter (BG40) was inserted into the light path between the light source and the filter block. For $35 \mathrm{~mm}$ photography, cells were photographed using TMAX 400 film (Eastman Kodak Co., Rochester, NY; pushed to 800 ASA in the development). For quantitative analyses, images were captured using a CH250 cooled CCD camera (Photometrics Ltd., Tucson, AZ) equipped with a Thompson $7883 \mathrm{CCD}$ chip. The details of our imaging system are described in Brown et al. (1992, 1993). Image processing and analysis were performed using the BDS-IMAGE software and application programs written in this laboratory using the BDS-IMAGE programming language. For maximum precision, all measurements of fluorescence intensity were performed on the 12 bit images generated by the camera. For presentation, monochrome images were scaled to 8 bits for display. Photographs of the images were then obtained either from the computer screen using TMAX 100 film (Eastman Kodak) and a $35 \mathrm{~mm}$ camera equipped with a macro lens or by an electronic imaging process performed at a local professional photographic laboratory (Quaker Photo, Philadelphia, PA).

Quantitative analysis using a segmented mask. For quantitative analyses, CCD images of the stained cells were acquired using a $25 \times, 0.8$ NA Plan-neofluar oil-immersion objective. To quantify fluorescence intensity along the length of an individual axon, we used image processing techniques to generate a mask of the axon based on the $\beta$-tubulin image (for cells double stained for MAP1b and $\beta$-tubulin) or based on total MAPIb staining (for cells double stained with the rabbit polyclonal antibody against MAPlb and the mouse monoclonal IgM antibody, $1 \mathrm{~B}$ $\mathrm{P}$, against a phosphorylation-dependent epitope on MAP1b). The techniques used to produce the mask were identical to those described by Brown et al. (1992). After generating the mask, it was divided into $\approx 8.5$ $\mu \mathrm{m}$-long segments and then overlaid on the original Texas red and fluorescein images. This allowed us to define segments in the fluorescent imagcs that corresponded to the segments in the mask. To correct for background fluorescence in each image, an average background pixel 


\section{B-Tubulin}
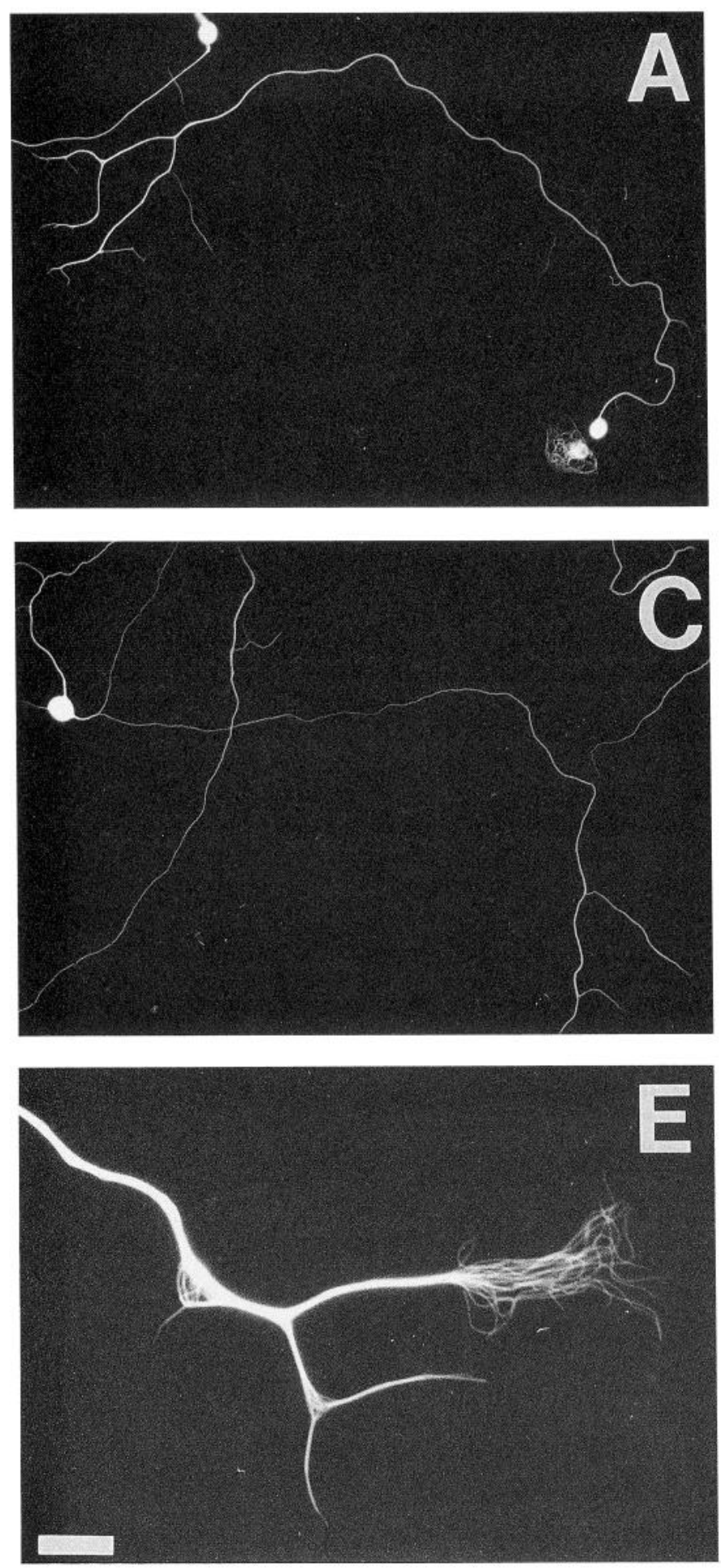

\section{MAP1b}
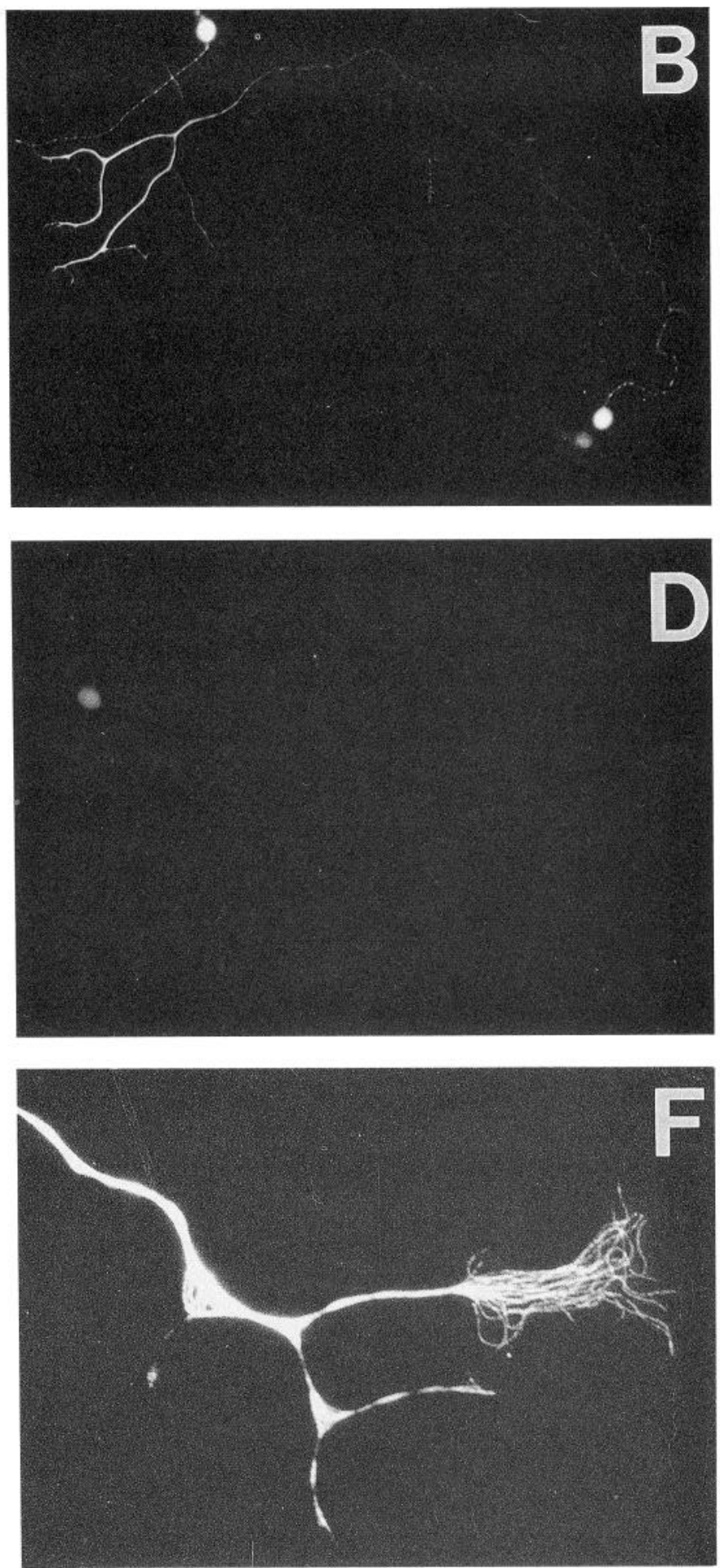

Figure 1. Immunolocalization of MAP1b in cultured neurons. Neurons were simultaneously fixed and extracted as described in the Materials and Methods and then stained with the monoclonal antibody against $\beta$-tubulin and the rabbit polyclonal antibody against MAPlb using staining condition 1 (see Materials and Methods). Shown are $35 \mathrm{~mm}$ photographs of $\beta$-tubulin $(A, C, E)$ and MAP1b $(B, D, F)$ staining of representative neurons. In $D$, the anti-MAP1b antibody was preadsorbed with brain MAPs prior to incubating with the cells. Scale bar: $30 \mu \mathrm{m}$ for $A-D ; 5.9 \mu \mathrm{m}$ for $E$ and $F$. 

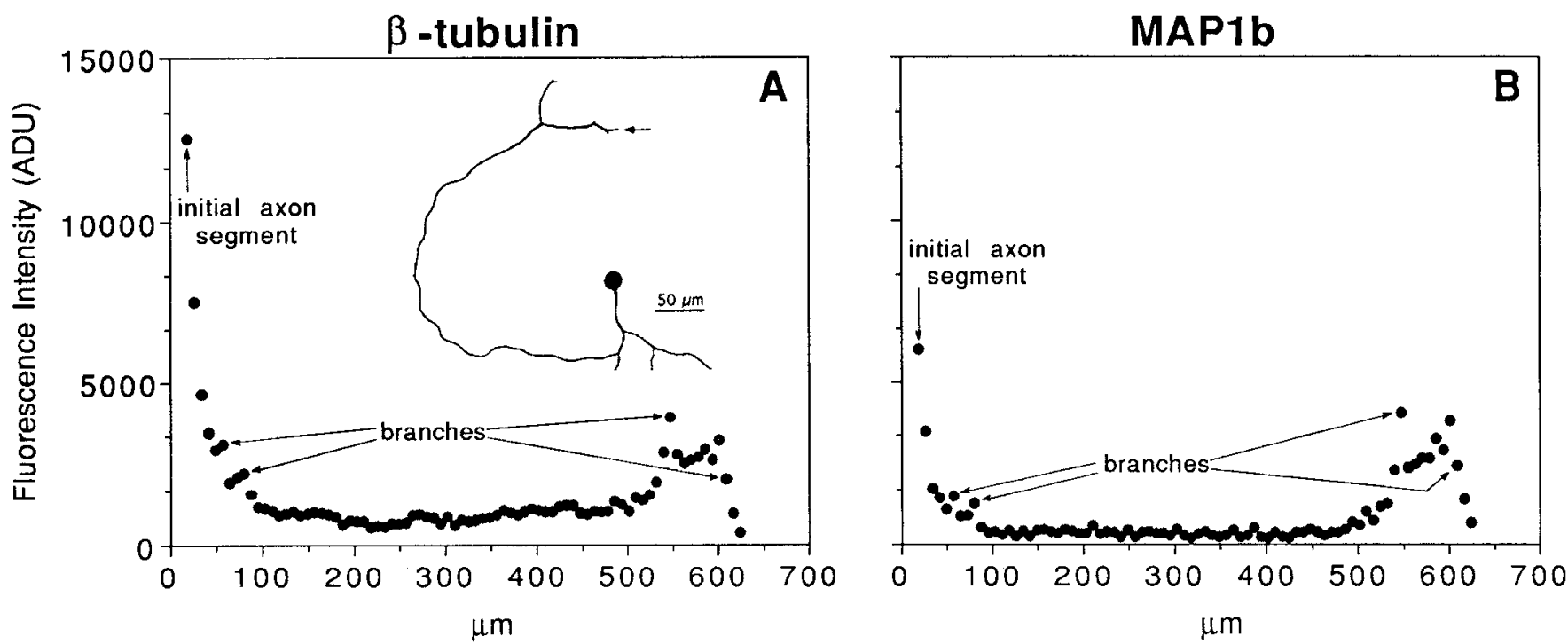

Figure 2. Quantitative analysis of the relative amounts of $\beta$-tubulin and MAPlb along the axon. Neurons simultaneously fixed and extracted were stained with the monoclonal antibody against $\beta$-tubulin and the rabbit polyclonal antibody against MAPlb using staining condition 1 (see Materials and Methods). Images of the cells were obtained with the cooled CCD camera and then analyzed using the segmented mask procedure. $A$ and $B$ show the total fluorescence intensity, in arbitrary analog-to-digital units $(A D U)$, for $\beta$-tubulin and MAPlb, respectively, in each axon segment plotted against distance along the axon. The inset in $A$ shows a computer-generated image of the neuron analyzed to generate these data. The analysis began at the cell body axon transition (initial segment of the axon) and extended to the tip of the axon (arrow in inset).

intensity was calculated for each segment and then subtracted from each pixel within that segment. Then, the total fluorescence intensity for the segments in each image was calculated by summing the corrected intensities of the pixels within each segment. Segments that contained fluorescent debris were omitted from analysis. The fluorescence intensity of each segment, measured as arbitrary analog-to-digital units (ADU), was then plotted against distance along the axon (see Figs. 2, 5, 8). The above procedures have been incorporated into a single interactive application program written in the BDS-IMAGE programming language. A synopsis of these procedures is presented in Brown et al. (1992), and a more detailed description will be provided upon request.

Measurements of axonal volume. Measurements of volume along the length of axons were based on $\beta$-tubulin-stained images of cells fixed without preextraction and double stained for $\beta$-tubulin and MAPIb. Briefly, the segmented mask procedure, in addition to measuring fluorescence intensity for each axon segment, also provides a measure of the area of each segment in pixels. Each segment is approximately rectangular in shape, with a length that is specified by the user as part of the analysis. We calculated the width of each segment based on its

Table 1. Distribution of total $\beta$-tubulin and MAP1b along the axon

\begin{tabular}{lcc} 
& \multicolumn{2}{c}{$\begin{array}{c}\text { Average } \pm \mathrm{SD} \\
\text { (minimum/maximum) }\end{array}$} \\
\cline { 2 - 3 } Profile parameters & $\beta$-Tubulin & MAPlb \\
\hline Length of distal region $(\mu \mathrm{m})^{a}$ & $118 \pm 21$ & $130 \pm 26$ \\
& $(91 / 163)$ & $(91 / 167)$ \\
Distance from axon tip of segment & $31 \pm 14$ & $23 \pm 13$ \\
containing peak ADU $(\mu \mathrm{m})$ & $(4 / 51)$ & $(4 / 51)$ \\
(Peak ADU distal axon) & $3.30 \pm 1.5$ & $13.10 \pm 8.4$ \\
(mean ADU axon shaft) & $(1.5 / 6.4)$ & $(3.9 / 31.2)$ \\
(Amount in distal axon) & $0.29 \pm 0.09$ & $0.53 \pm 0.15$ \\
(total amounl in axon) & $(0.22 / 0.48)$ & $(0.34 / 0.76)$
\end{tabular}

The data were obtained from 10 axons simultaneously fixed and extracted, doublestained with the mouse monoclonal antibody against $\beta$-tubulin and the rabbit polyclonal antibody against MAP1b using staining condition 1 (see Materials and Methods), and then analyzed using the segmented mask procedure. The average length of the axons analyzed was $583 \pm 79 \mu \mathrm{m}$ (range $=436-700 \mu \mathrm{m})$. All data are based on the fluorescence intensity measurements for MAP1b and $\beta$-tubulin. "The lengths of the distal regions were determined as described in the Results. specified length and measured area. We converted the value for the width from pixels into micrometers, and then, assuming that the axon is cylindrical in shape, used the width of each segment as a measure of its diameter to compute segment volume. We chose a cylindrical model because cross sections of axons of cultured neurons have a circular contour (Black et al., 1984). This model is adequate for most of the axon, except at branch points and at the growth cone. The axons that we studied branched minimally along their length, and the growth cone was containcd in the single, most distal segment of the axon. We have not corrected our volume determinations for segments containing branch points or the growth cone for deviations from a cylindrical shape. The resulting volume measurements were used to generate plots of volume as a function of position along the axon and to normalize the fluorescence intensity for $\beta$-tubulin and MAP1b along the axon to axon volume (see Results and Fig. 3).

\section{Results}

\section{MAPlb localization in growing axons}

Figure 1 shows immunofluorescent images of neurons simultaneously fixed and extracted and then double stained to reveal MAP $1 b$ and $\beta$-tubulin. As expected, $\beta$-tubulin is present throughout the neuron (Fig. $1 A, C$ ), and in regions where the cell is especially flattened, which occur sporadically along the axon shaft and especially at the growth cone, $\beta$-tubulin staining has the filamentous appearance characteristic of MTs (Fig. 1E). $\beta$-Tubulin staining was continuous along the length of the axon, and typically was greater in its proximal and distal regions compared to the axon shaft.

MAP1b was also present all along the axon, and in spread regions of axonal cytoplasm it exhibited a clear filamentous character. This was especially apparent in the growth cone, where MAP1b staining colocalized precisely with MTs (Fig. $1 E, F$ ). In fact, in every growth cone in which individual MTs could be observed, MAPlb decorated all of these MTs, and the MAPlb staining extended to or very near the distal end of these polymers. However, unlike tubulin staining, which was uniform along individual MTs (see also Brown et al., 1993), MAP1b staining exhibited a patchy appearance along individual MTs. The patchy appearance presumably reflects the periodicity of 

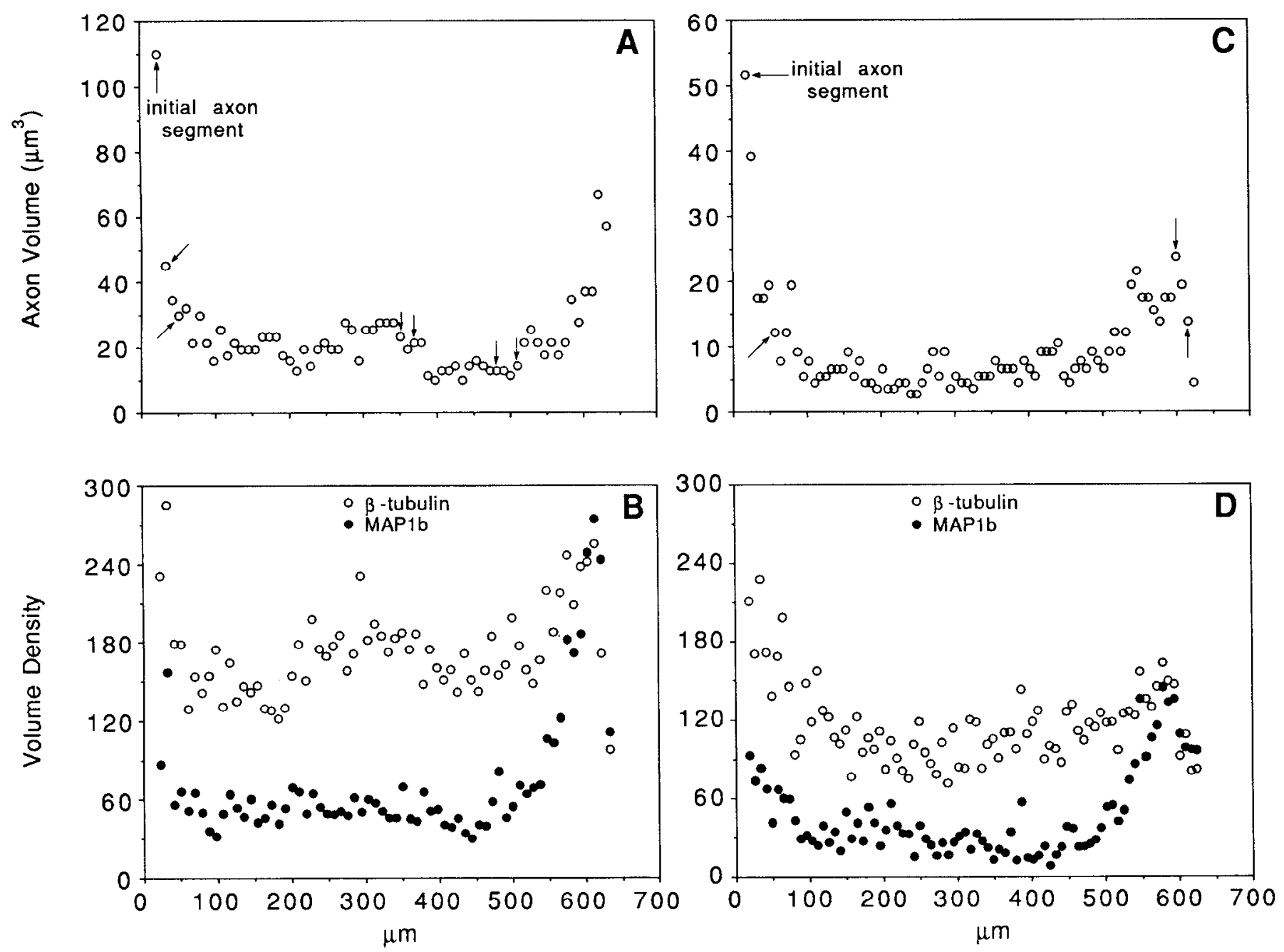

Figure 3. Quantitative analysis of the volume densities of $\beta$-tubulin and MAPlb along the axon. Neurons simultaneously fixed and extracted were stained with the monoclonal antibody against $\beta$-tubulin and the rabbit polyclonal antibody against MAPlb using staining condition 1 (see Materials and Methods), and then analyzed using the segmented mask procedurc. For cach axon analyzed, we determined the volume (in $\mu \mathrm{m}^{3}$ ), the fluorescence intensity due to $\beta$-tubulin, and the fluorescence intensity due to MAPlb of each axon segment. To obtain a measure of the volume density of $\beta$-tubulin and MAPlb for each axon segment, the fluorescence intensities due to $\beta$-tubulin and MAPlb for each segment were divided by segment volume. The resulting segment volumes and volume densities were then plotted against distance along the axon. Shown are the results from two representative neurons; $A$ and $B$ show the results from one neuron, while $C$ and $D$ show the results from a different neuron (the data in $C$ and $D$ are from the same cell used to obtain the data in Fig. 2). $A$ and $C$ show the volume of each segment plotted against distance along the axon. $B$ and $D$ show the volume densities of $\beta$-tubulin and MAP1b in each segment plotted against distance along the axon. The unlabeled arrows in $A$ and $C$ indicate branch points.

MAP1b binding along the surface of MTs. A similar colocalization along MTs was also suggested in flattened regions of the axon shaft (Fig. $1 F$ and data not shown). Axonal staining for MAPlb could be prevented by preincubating the anti-MAPlb antibody with a MAP fraction prepared from the brains of newborn rat pups (Fig. 1D).

The amount of MAPl $b$ in the axon varied dramatically along its length. This can be seen qualitatively in Figure $1 B$, in which MAPlb staining is more intense in the proximal and distal regions of the axon compared to the axon shaft. Quantitative analyses using the segmented mask procedure confirmed this regional variation in MAP1b content of the axon, and allowed us to calculate several parameters of MAPlb as well as $\beta$-tubulin distribution in growing axons (Fig. 2, Table 1). MAP1b and $\beta$-tubulin fluorescence was greatest in the cell body. Moving out from the cell body into the axon, the fluorescence intensity due to both MAPlb and $\beta$-tubulin declined over an average distance of 50-60 $\mu \mathrm{m}$ to a level that was relatively constant until $120-$ $130 \mu \mathrm{m}$ from the axon tip, where the fluorescence intensity due to both MAPlb and $\beta$-tubulin began to increase, reaching a peak value that was, on average, $20-30 \mu \mathrm{m}$ from the axon tip (see Table 1). The peak values of $\beta$-tubulin and MAP1b staining in the proximal axon were, on average, 7.54 and 9.54 times, respectively, that in the axon shaft, and the amounts of $\beta$-tubulin and MAP $1 \mathrm{~b}$ in the proximal axon represented, on average, $21 \%$ and $16 \%$, respectively, of the total amount in the axon. The peak values of $\beta$-tubulin and MAP1b staining in the distal axon were, on average, 3.30 and 13.10 times, respectively, that in the axon shaft, and the amounts of $\beta$-tubulin and MAPlb in the distal axon represented, on average, $29 \%$ and $53 \%$, respectively, of the total amount in the axon (Table 1).

We have defined three regions of the axon based on these fluorescence intensity plots, the proximal axon, the distal axon, and the axon shaft. The proximal axon extends from the initial 


\section{MTs}
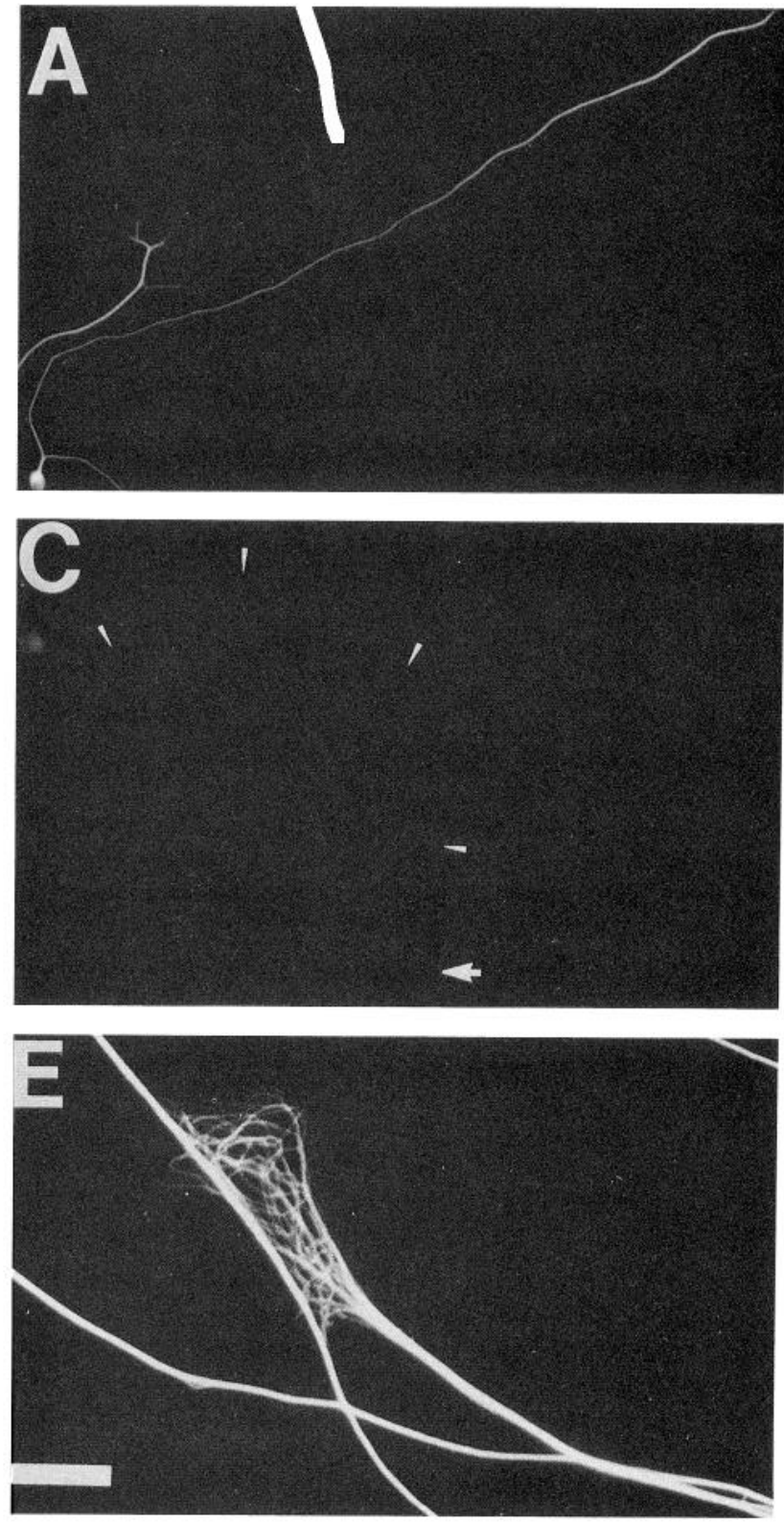

MAP1b
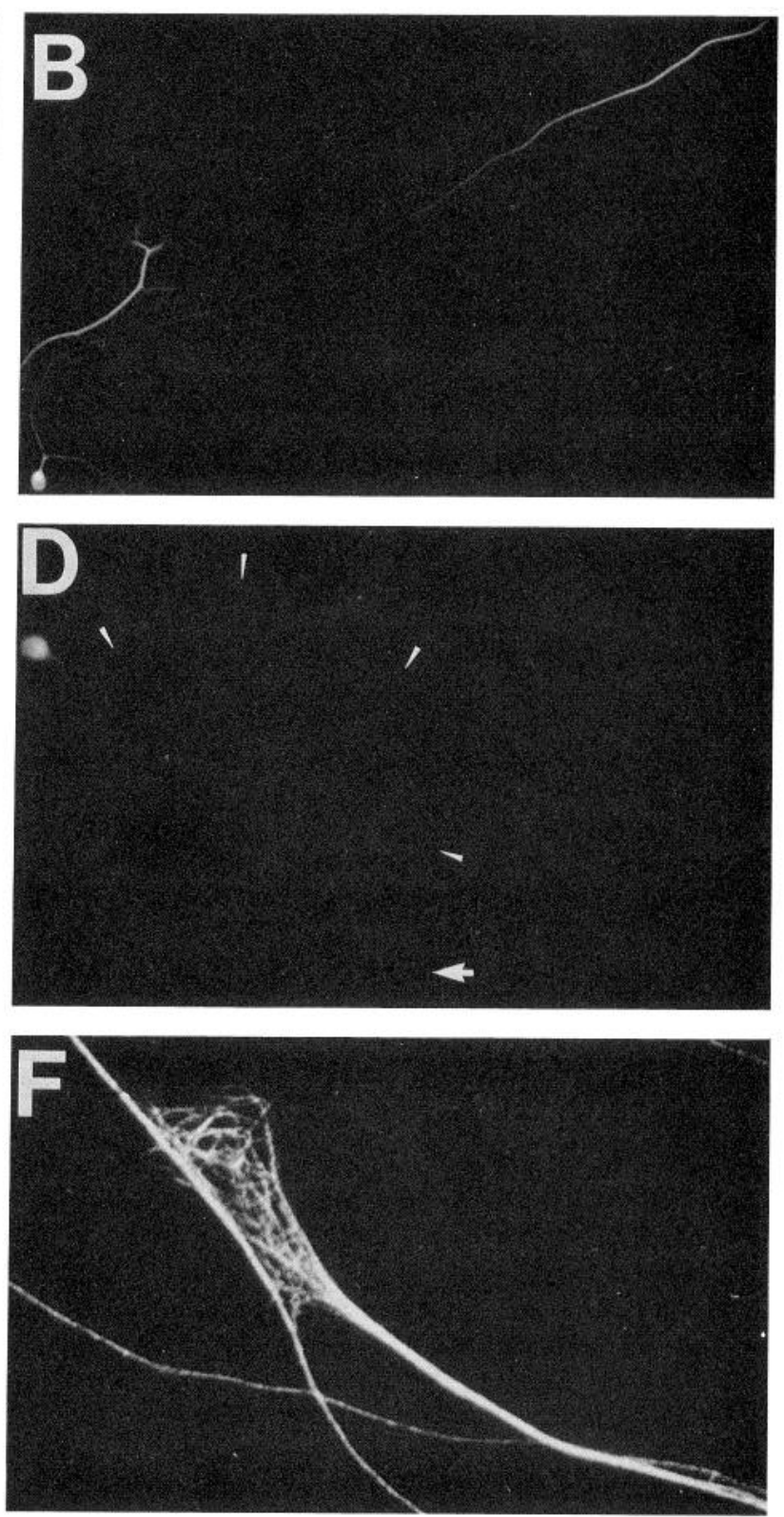

Figure 4. Immunolocalization of assembled MAP1b in cultured neurons. Neurons were extracted under MT-stabilizing $(A, B, E, F)$ or -destabilizing $(C, D)$ conditions as described in the Materials and Methods, fixed, and then stained with the monoclonal antibody against $\beta$-tubulin and the rabbit polyclonal antibody against MAP1b using staining condition 1 (see Materials and Methods). Shown are CCD images ( $A-D)$ and $35 \mathrm{~mm}$ images $(E, F)$ depicting the $\beta$-tubulin $(A, C, E)$ and MAP1b $(B, D, F)$ staining. In $C$ and $D$, which depict a neuron extracted under MT-depolymerizing conditions, arrowheads are used to indicate the axon, and the arrow indicates the axon tip. Scale bar: $60 \mu \mathrm{m}$ for $A-D ; 7.9 \mu \mathrm{m}$ for $E$ and $F$.

axon segment to the point where the fluorescence intensity declines to a constant level. The distal axon extends from the point where the fluorescence intensity begins to rise to the end of the axon. The axon shaft lies between the proximal and distal axon regions. The values obtained for the measured parameters of $\beta$-tubulin staining of axons are very similar to those obtained for MAP1b staining (see above and Table 1), except for the magnitude of the increase in fluorescence intensity between the axon shaft and the distal axon. In this regard, MAPlb levels increased to a much greater extent than did $\beta$-tubulin levels, and the fraction of MAP1b present in the distal axon was greater than that for $\beta$-tubulin.

The variation in the amount of MAPlb along the axon is not due merely to a corresponding variation in axonal volume. This was initially suggested by the lack of correspondence between the fluorescence intensity profiles of MAP1b and $\beta$-tubulin, especially in the region of the distal axon. To evaluate this issue directly, we have calculated the volume density of MAP1b as a function of distance along the axon (see Materials and Methods). Visual inspection of axons by DIC or phase microscopy 
or by immunofluorescence microscopy after staining for $\beta$-tubulin (see Fig. $1 A, C$ for example) suggested that the axon was thicker in its proximal and distal regions compared to the axon shaft, and measurements of axon volume versus distance along the axon confirmed that this is the case (Fig. $3 A, C$ ); the volume of the axon is greater in the proximal and distal regions than in the axon shaft.

Plots of the volume density of MAP $1 \mathrm{~b}$ along these same axons do not conform to a straight line of slope $=0$ (Fig. $3 B$ ), indicating that the variations in amount of MAPlb along the axon are not due entirely to a corresponding variation in axonal volume. Rather, the volume density of MAP $1 b$ typically is higher in the proximal and distal axon regions compared to the axon shaft. This result is particularly striking for the distal axon, in which the peak volume density for MAPlb is, on average, 6.7 -fold (range $=3-12$ ) that of the axon shaft. Thus, MAPIb is more concentrated in the proximal and distal axon regions compared to the axon shaft. The situation for $\beta$-tubulin was variable. In 7 of the 10 axons examined, the volume density of $\beta$-tubulin was higher in the proximal and distal axon regions compared to the axon shaft, but the average increase in volume density of $\beta$-tubulin distally, 1.8-fold (range $=1.6-2.2$ ), was much less than that observed for MAPlb. In the other three axons, little or no variation in the volume density of $\beta$-tubulin was observed along the axon.

\section{$M A P I b$ is enriched on MTs in the distal axon}

To determine whether the variation in the amount of MAPIb along the axon reflects a corresponding variation in the amount of MAPIb on axonal MTs, neurons were permeabilized under MT-stabilizing conditions to extract unassembled MT proteins, fixed, and then double stained for MAPlb and $\beta$-tubulin. We then used the segmented mask procedure to quantify the $\mathrm{M} \Lambda \mathrm{P} 1 \mathrm{~b}$ and $\beta$-tubulin fluorescence in consecutive segments of the axon, and computed a ratio of the MAP1b fluorescence to $\beta$-tubulin fluorescence for each segment. This ratio represents a relative measure of the amount of MAP $1 b$ on the MT polymer contained in each segment. Plots of this ratio versus distance along the axon will reveal whether the MAPIb content of MTs varies along the axon. The validity of this approach requires that MAPIb remain on the MTs during extraction and that unassembled MT proteins are effectively removed from the neuron during extraction. We first present the results of experiments examining these methodologic issues.

Figure $4, A$ and $B$, shows images of a representative neuron that was extracted under MT-stabilizing conditions and then double stained to reveal MTs and MAPlb. MTs, as revealed by $\beta$-tubulin staining, were observed throughout the cell body and the axon (see also Brown et al., 1992), and in flattened regions of the axon and in the growth cone, individual MTs were readily visualized (see Fig. $4 E$ ). MAP1b staining was also apparent throughout the neuron, and in the axon staining was strongest in its distal region. Staining for MAP $1 \mathrm{~b}$ could be prevented by preincubating the anti-MAPlb antibody with MAPs prepared from the brains of newborn rat pups (data not shown). In flattened regions of the axon shaft and in the growth cone, MAPlb staining colocalized with MTs (Fig. $4 E, F$ and data not shown). MAP1b staining of MTs exhibited a patchy appearance that closely resembled that seen in cells fixed without preextraction (compare Figs. $1 F, 4 F$ ). Clearly, MAPlb remains on MTs during the extraction procedure. Furthermore, in spread regions where the MT localization of MAPIb is apparent, there
Table 2. Distribution of assembled $\beta$-tubulin and MAP1b along the axon

\begin{tabular}{lcc} 
& \multicolumn{2}{l}{$\begin{array}{l}\text { Average } \pm \text { SD } \\
\text { (Minimum/maximum) }\end{array}$} \\
\cline { 2 - 3 } Profile parameters & $\beta$-Tubulin & MAPIb \\
\hline Length of distal region $(\mu \mathrm{m})^{\prime \prime}$ & $154 \pm 49$ & $147 \pm 47$ \\
& $(97 / 241)$ & $(87 / 241)$ \\
Distance from axon tip of segment & $36 \pm 22$ & $32 \pm 19$ \\
containing peak ADU $(\mu \mathrm{m})$ & $(8 / 78)$ & $(8 / 79)$ \\
(Peak ADU distal axon)/ & $3.90 \pm 2.1$ & $14.1 \pm 12.2$ \\
(mean ADU axon shaft) & $(1.7 / 7.3)$ & $(3.5 / 46.8)$
\end{tabular}

The data were obtained from 13 axons extracted under MT-stabilizing conditions, fixed, double stained with the mouse monoclonal antibody against $\beta$-tubulin and the rabbit polyclonal antibody against MAP1b using staining condition 1 (see Materials and Methods), and then analyzed using the segmented mask procedure. The average length of the axons analyzed was $593 \pm 137 \mu \mathrm{m}$ (range $=391-782$ $\mu \mathrm{m})$. The data for MAPIb and $\beta$-tubulin are based on the measurements of total fluorescence intensity, in $\mathrm{ADU}$, due to MAPIb and $\beta$-tubulin staining along the axon (see Fig. $5 A, C$ for example).

"The distal region for MAP1b and $\beta$-tubulin extended from the segment where the fluorescence intensity values for MAPIb or $\beta$-tubulin, respectively, began to increase to the end of the axon.

is no indication of MAP $1 \mathrm{~b}$ concentrated on structures other than MTs (Figs. $1 F, 4 F$ ).

To determine whether unassembled MT proteins are effectively removed from the neuron during permeabilization, cells were extracted in the presence of $1 \mathrm{~mm} \mathrm{CaCl}_{2}$ to depolymerize their MTs. If the extraction of unassembled tubulin is effective, then the cells should contain little tubulin relative to cells extracted under MT-stabilizing conditions. We found that neurons extracted under MT-depolymerizing conditions showed very $\operatorname{dim} \beta$-tubulin fluorescence in their cell bodies, and their axons showed no detectable fluorescence (Fig. $4 C$ ), whereas neurons permeabilized under MT-stabilizing conditions stained brightly for $\beta$-tubulin in their cell bodies and axons (Fig. 4A). To evaluate quantitatively the effectiveness of the extraction procedure, we compared the total $\beta$-tubulin fluorescence in the cell bodies of neurons extracted under the different conditions. This analysis revealed that $\approx 98 \%$ of the $\beta$-tubulin comprising the MT polymer of the cell body is extracted under conditions that depolymerize this polymer (this value is hased on analyses of 7 neurons extracted under depolymerizing conditions and 10 cells extracted under stabilizing conditions). Clearly, unassembled tubulin is effectively removed during extraction. Thus, the $\beta$-tubulin staining remaining after extraction under stabilizing conditions is due specifically to MTs.

The behavior of MAPlb during extraction under MT-depolymerizing showed both similarities and differences with regard to that shown by tubulin. The one difference involved the cell body and proximal axon region, which stained relatively brightly for MAPlb after extraction under MT-depolymerizing conditions (Fig. 4D). Quantitative analyses revealed that the MAP1b remaining in cell bodies after extraction under depolymerizing conditions was $47 \%$ of that in cell bodies extracted under MTstabilizing conditions. Thus, substantial levels of MAP1b remain in the cell body after extraction under conditions that depolymerize $\approx 98 \%$ of its MT polymer, and some MAP $1 \mathrm{~b}$ also remains in the proximal axon. This MAPlb may have been associated with the small amount of $\mathrm{Ca}^{2+}$-stable MT polymer present in these neurons (Black et al., 1984; see also above). However, we consider this unlikely because the MAP1b re- 



Figure 5. Quantitative analysis of the relative amounts of MT polymer and assembled MAP1b along the axon. Neurons extracted under MTstabilizing conditions as described in the Materials and Methods were stained with the monoclonal antibody against $\beta$-tubulin and the rabbit polyclonal antibody against MAPlb using staining condition I (see Materials and Methods), imaged with the cooled CCD camera, and then analyzed using the segmented mask procedurc. Shown are the results from two representative neurons (the data in $C$ and $D$ are from the cell shown in Fig. $4 A, B$ ). The upper graphs show the fluorescence intensities values, in ADU, for assembled $\beta$-tubulin and assembled MAPlb in consecutive segments of the axon, plotted against distance along the axon. The lower graphs show the ratio of assembled MAP1b fluorescence to the assembled $\beta$-tubulin fluorescence for each segment, plotted against distance along the axon. Because the fluorescence intensities were measured in ADU, the ratio values provide a relative measure of the MAPIb content of MTs along the axon.

maining in the cell body and proximal axon after extraction with $1 \mathrm{~mm} \mathrm{CaCl}$, is diffuse in localization, and does not show an association with discrete structures, even in flattened regions of cytoplasm. Because the nonextracted MAP1b of the cell body and proximal axon cannot be unambiguously attributed to MTs, we did not consider these regions for MT analysis.

By contrast with the situation in the cell body and proximal axon, the axon shaft and distal region of the axon stained very dimly for MAPlb after extraction under MT-depolymerizing conditions (Fig. 4D). Although the fluorescence was too low to measure reliably, we have estimated the extent of cxtraction under MT-depolymerizing conditions based on the following considerations. After extraction under MT-stabilizing conditions, the peak staining for MAPlb in the distal axon is approximately 14 times that in the axon shaft (Table 2). The staining of the distal axon for MAP1b after extraction under MT-depolymerizing conditions was less than the staining of the axon shaft for total cytoskeletal MAPlb (comapre Fig. $4 B, D$ ). Thus, we estimate that extraction under MT-depolymerizing conditions removes $\geq 93 \%$ of the MAP $1 \mathrm{~b}$ from the axon. These observations indicate that unassembled MAPlb is effectively removed from the axon shaft and distal axon by our extraction procedures, and that the MAP $1 \mathrm{~b}$ remaining after extraction reflects MAP1b that is assembled into MTs.

We have used the segmented mask procedure to calculate the relative amounts of total MT polymer and assembled MAPIb in the axon shaft and distal axon and to determine whether the relative amount of MAPIb on $M$ I's varies along the length of the axon. Figure 5 shows the analysis for two axons, and Table 2 summarizes the data for the population of axons studicd. The total fluorescence intensity profiles for MT polymer and MAP $1 \mathrm{~b}$ are quite similar to each other in overall shape (Fig. 5A,C). Both parameters are relatively constant along the length of the axon until $\approx 150 \mu \mathrm{m}$ from the axon tip, at which point they begin to increase. The total amount of polymer and the amount of assembled MAP1b each peaked at variable distances from the axon tip (see Table 2), and in some cases declined substantially over the most distal several micrometers of the axon (Fig. 5). 


\section{Tubulin}
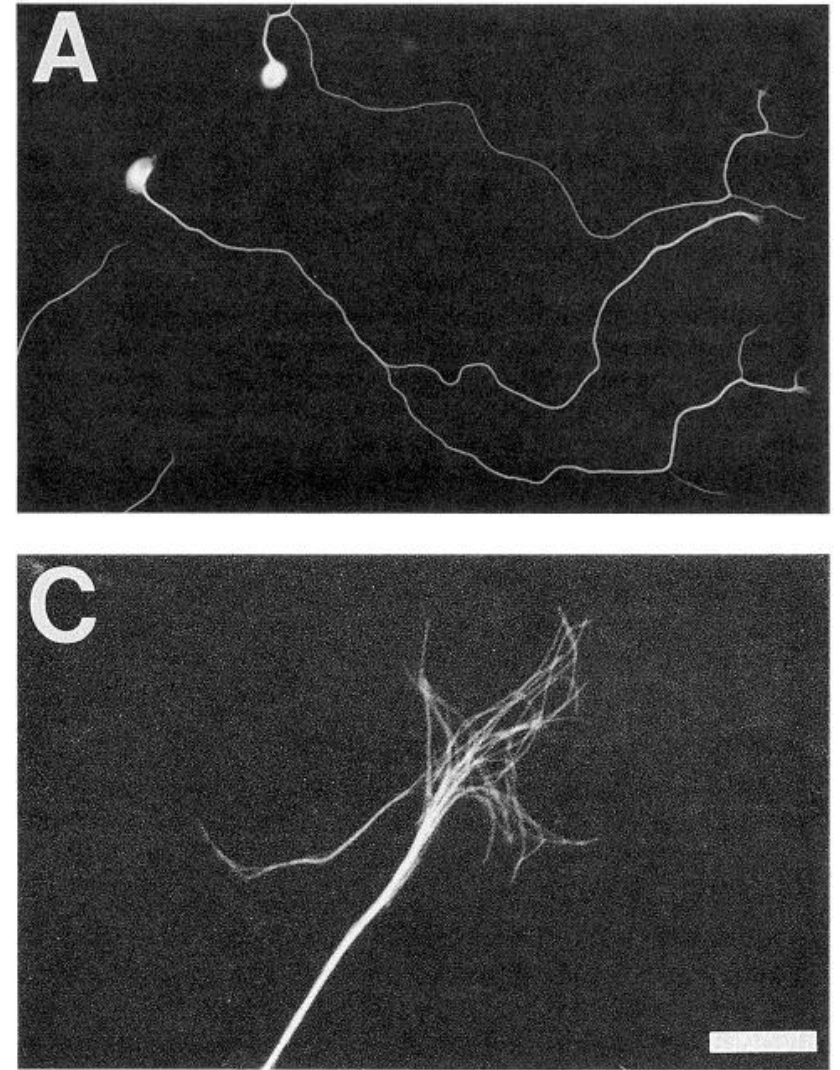

\section{Phosphorylated MAP1b}
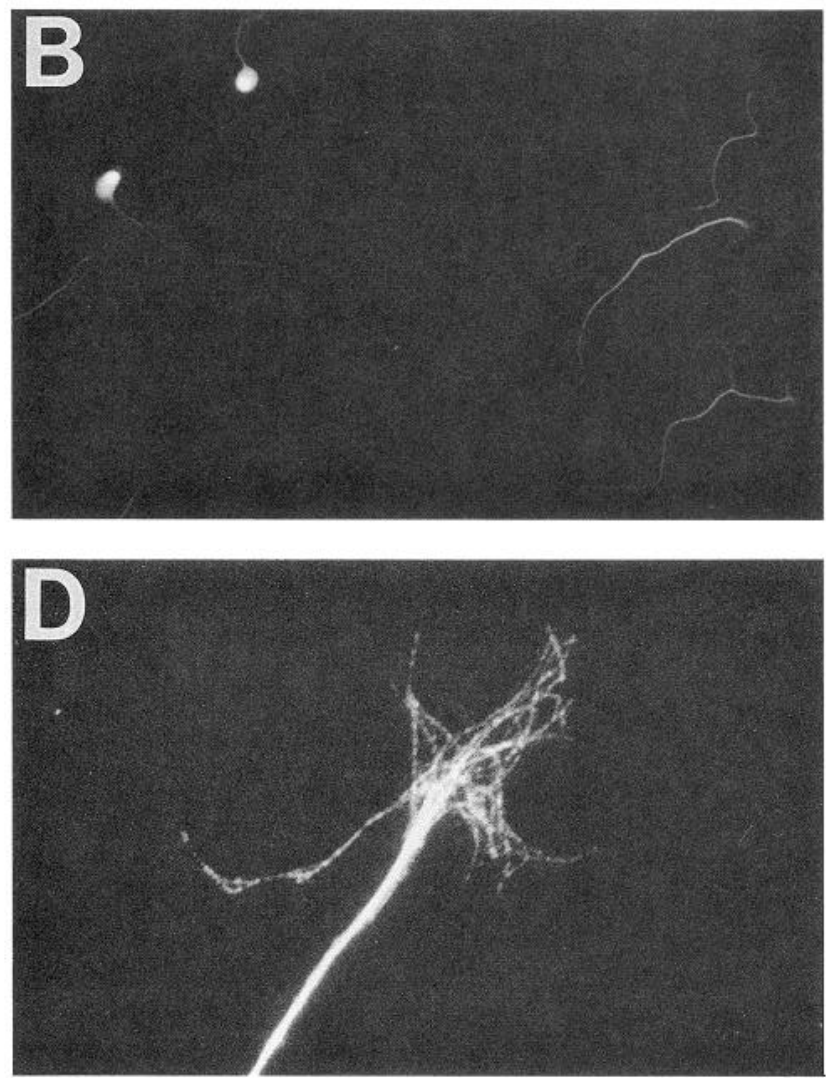

Figure 6. Localization of phosphorylated MAP1b along the axon. Shown are images of neurons simultaneously fixed and extracted and then double stained with the 1B-P monoclonal antibody against a phosphorylation-dependent epitope of MAP1b $(B, D)$ and either an antibody against $\beta$-tubulin $(A)$ or tyrosinated $\alpha$-tubulin $(C)$. The neurons in $A$ and $B$ were stained according to condition 4 , while the neurons in $C$ and $D$ were stained according to condition 2 (see Materials and Methods). Scale bar: $62.6 \mu \mathrm{m}$ for $A$ and $B ; 8.5 \mu \mathrm{m}$ for $C$ and $D$.

[A more detailed description of the variation in amount of total polymer along the axon will be presented in a separate communication (A. Brown and M. M. Black, unpublished observations).]

Although the fluorescence intensity profiles for total polymer and assembled MAP1b resembled each other in overall shape, the amount of assembled MAPIb increased to a much greater extent in the distal axon than did total polymer (Table 2). As one measure of this, we compared the peak fluorescence intensity in the distal axon with the average intensity along the axon shaft for both assembled MAP1b and total polymer. The peak levels of MT polymer in the distal axon were, on average, 3.9 times that in the axon shaft, whereas the peak levels of assembled MAP1b were, on average, 14.1 times that in the shaft. To obtain a more complete picture of the variation in the relative amount of MAP1b on MTs along the axon, we divided the MAP $1 \mathrm{~b}$ fluorescence by the $\beta$-tubulin fluorescence for each axon segment and then graphed the resulting ratio values against distance along the axon. For each segment, the magnitude of the ratio provides a relative measure of the amount of MAP1b on the polymer contained within that segment. The ratio is relatively constant along the axon, until $164 \pm 51 \mu \mathrm{m}$ (range $=$ $100-237 \mu \mathrm{m}$ ) from the axon tip, at which point the ratio begins to increase, reaching a peak value at $20 \pm 12 \mu \mathrm{m}$ (range $=4$ $43 \mu \mathrm{m}$ ) from the axon tip. The peak ratio in the distal axon was $3.7 \pm 1.5$ times (range $=2.4-7.8$ ) that in the axon shaft.

\section{Phosphorylation of MAPIb varies along the axon}

The increase in the relative MAP1b content of MTs in the distal axon may reflect the fact that the concentration of MAP1b is greater in the distal axon compared to the axon shaft (Fig. 3). It is also possible that factors in addition to concentration influence the association of MAPIb with MTs in different regions of the axon. In this regard, MAPlb is phosphorylated (DiazNido et al., 1988; Sato-Yoshitake et al., 1989; Fischer and Romano-Clarke, 1990; Riederer et al., 1990), and the phosphorylated isoform(s) appears enriched in the distal end of the axon (Mansfield et al., 1991). These considerations raise the possibility that variations in the extent of MAPlb phosphorylation along the axon may also contribute to the variation in the relative MAP1b content of MTs along the axon. To test this possibility, we have examined the phosphorylation of MAP1balong 


\section{Total MAP1b}

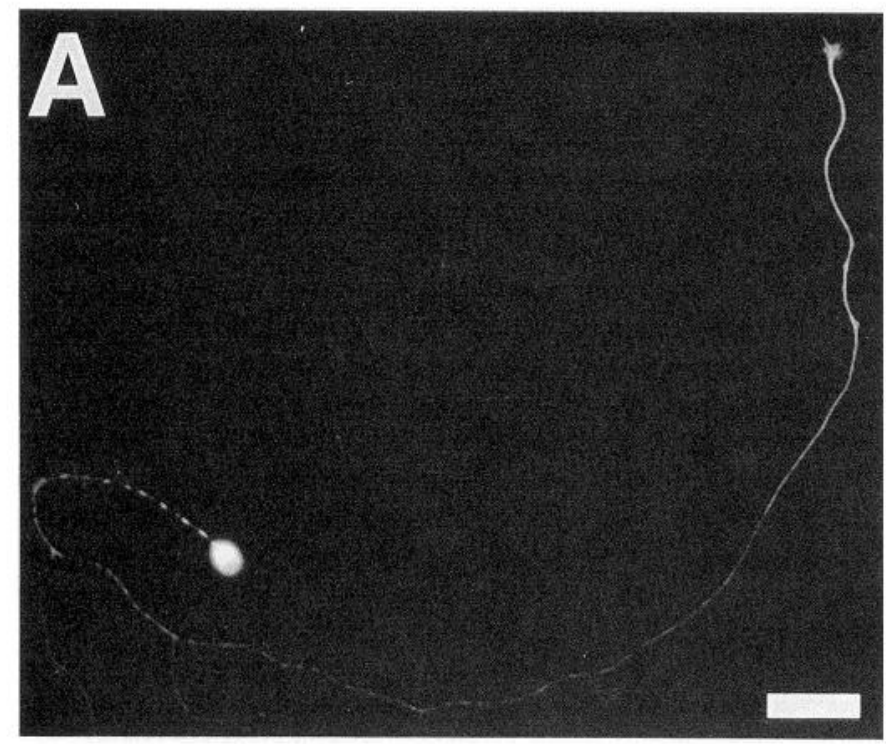

\section{Phosphorylated MAP1b}

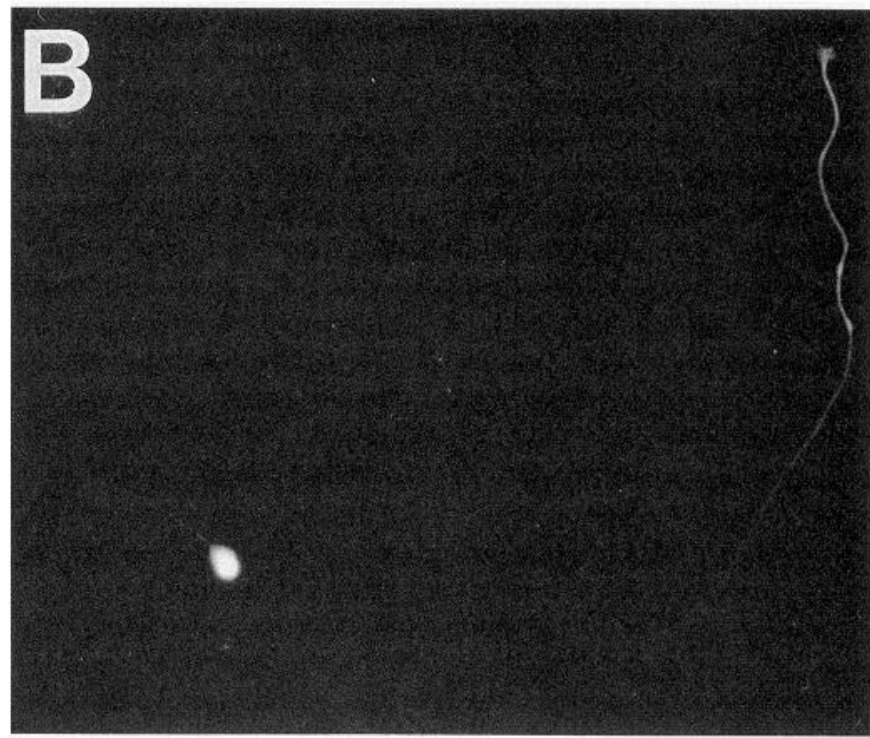

Figure 7. Double staining of axons for total MAP1b and phosphorylated MAPlb. Shown are images from a representative neuron simultaneously fixed and extracted, and then double stained with the polyclonal antibody against total MAPIb $(A)$ and the $1 \mathrm{~B}-\mathrm{P}$ monoclonal antibody against a phosphorylation-dependent epitope of MAPlb $(B)$ using staining condition 3 (see Materials and Methods). Scale bar, $38 \mu \mathrm{m}$.

the axon. We focused on MAP1b phosphorylated at a phosphorylation-dependent epitope defined by the 1B-P monoclonal antibody.

Figure 6 shows immunofluorescent images of the localization of MAP1b phosphorylated at the 1B-P epitope. Phosphorylated MAP1b was detected all along the axon, but was present at highest amounts in the distal axon (Fig. $6 B$ ). In spread regions of the axon and in the growth cone where individual MTs could be visualized, staining for MAPIb phosphorylated at the 1B-P epitope clearly colocalized with MTs (Fig. 6C,D).

To determine whether the proportion of total MAPlb that is phosphorylated at the $1 \mathrm{~B}-\mathrm{P}$ epitope varies along the axon, neurons were double stained with the 1B-P mouse monoclonal antibody and the rabbit polyclonal antibody against total MAPIb using staining condition 3 (see Materials and Methods), and then analyzed quantitatively using the segmented mask procedure. Figure 7 shows images of a representative neuron double stained in this manner. As seen qualitatively in Figure 7 and confirmed quantitatively in Figure 8, $A$ and $C$, the distribution of phosphorylated MAP1b increased dramatically in the distal end of the axons and resembled the distribution for total MAPIb. To evaluate the relative changes in the phosphorylation of MAPIb along the axon, we computed a ratio of the phosphorylated MAP $1 \mathrm{~b}$ fluorescence to the total MAP $1 \mathrm{~b}$ fluorescence for each segment of the axon and then graphed the resulting ratio versus distance along the axon (Fig. $8 B, D$ ). These analyses show that the proportion of total MAPlb that is phosphorylated at the 1B-P epitope increases progressively along the axon shaft to reach a peak in the distal part of the axon. The position of the peak occurred at variable distances from the growth cone. Similar results were also obtained in a limited number of anal- yses of neurons extracted under MT-stabilizing conditions and then double stained to reveal total MAP1b and phosphorylated MAPIb (data not shown). These data show that phosphorylated MAP1b is concentrated in the distal part of growing axons, and that the proportion of total MAPlb that is phosphorylated increases in a more or less gradual manner along the axon, beginning $\approx 100 \mu \mathrm{m}$ from the cell body.

\section{Discussion}

Our results show that MAP1b has a nonuniform distribution in growing axons. Specifically, MAPlb is present at relatively low levels along the axon shaft, showing relatively little variation along its length. However, beginning $\approx 130 \mu \mathrm{m}$ from the axon tip, the amount of MAP1b begins to increase sharply, and peaks slightly proximal to the growth cone at relative levels that are, on average, an order of magnitude greater than those in the axon shaft. This is true when considering the total MAPlb in the axon (Table 1) or just the MAP1b assembled into MTs (Table 2). The volume of the axon is also greater in its distal region compared to the shaft (Fig. 3). However, the increase in the amount of MAP1b in the distal axon exceeds by severalfold the increase in axon volume (Fig. 3), indicating that the concentration of MAPIb in the distal region of growing axons is indeed greater than that along the axon shaft. Furthermore, the phosphorylated isoform of MAP1b defined by the 1B-P antibody is also more enriched in the distal region of the axon than anywhere else along its length. An enrichment of MAP1b in the distal part of growing axons has also been inferred on the basis of qualitative immunostaining studies with hippocampal (Fischer and Romano-Clarke, 1991) and cerebral cortical (Mansfield et al., 1992) neurons. Thus, the general features of MAP1 b localization 

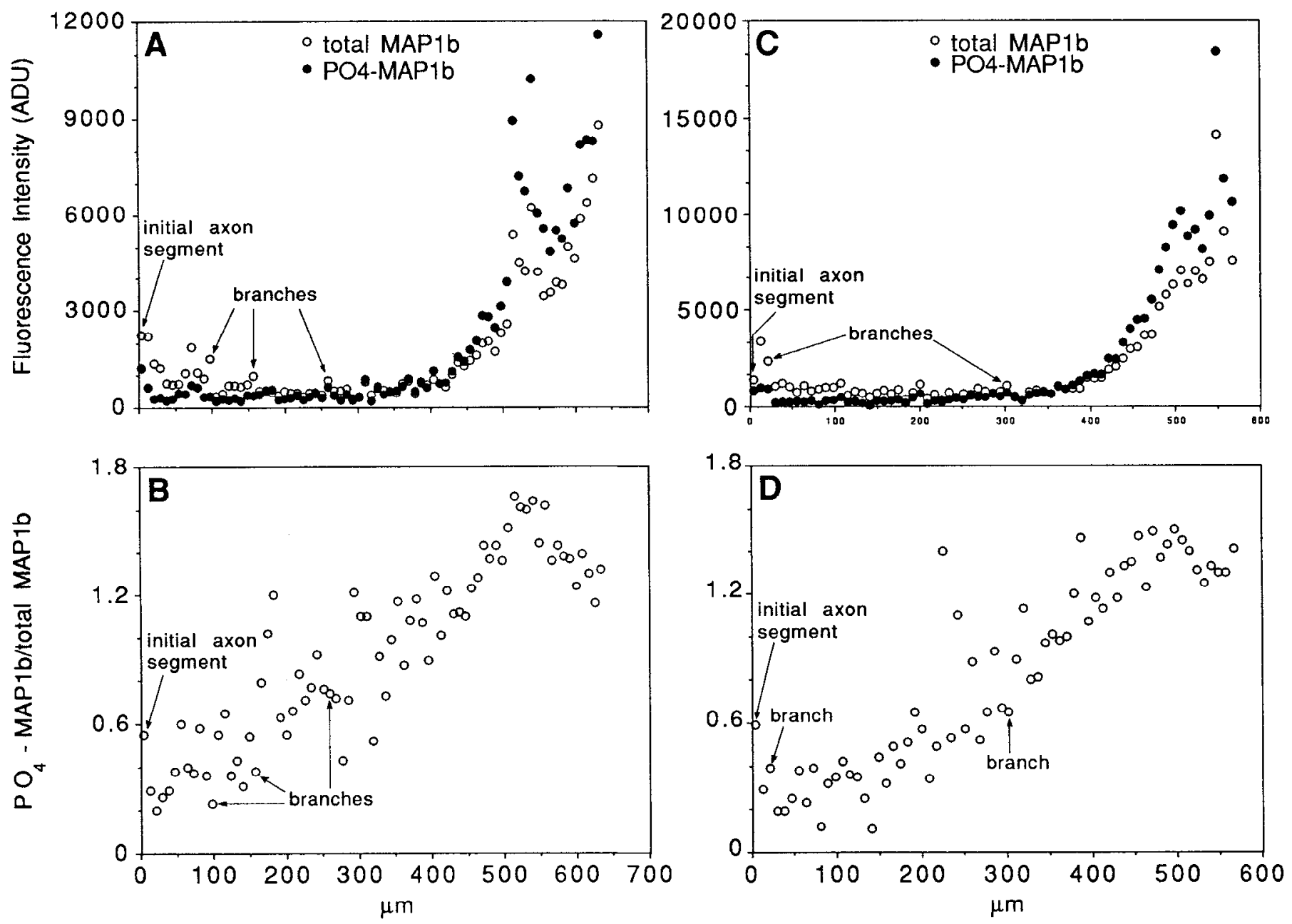

Figure 8. Quantitative analysis of the relative amounts of total and phosphorylated MAPlb along the axon. Neurons simultaneously fixed and extracted were stained with the 1B-P monoclonal antibody against phosphorylated MAPIb and the rabbit polyclonal antibody against total MAPIb using staining condition 3 (see Materials and Methods), imaged with the cooled CCD camera, and then analyzed using the segmented mask procedure. Shown are the results from two representative neurons (the data in $C$ and $D$ are from the cell shown in Fig. 7). The upper graphs show the fluorescence intensity values, in ADU, due to total MAPIb and phosphorylated MAP1b in consecutive segments of the axon, plotted against distance along the axon. The lower graphs show the ratio of phosphorylated MAP1b fluorescence to the total MAP1b fluorescence for each axon scgment, plottcd against distance along the axon. Bccause the fluorescence intensities were measured in ADU, the ratio values provide a relative measure of the proportion of total MAP1b that is phosphorylated at the 1B-P epitope along the axon.

described here for growing sympathetic neurons are likely to apply to other types of growing neurons.

We assume that the enrichment of MAP1b and its phosphorylated isoform selectively in the distal region of growing axons has implications with regard to the function of MAPIb in axon growth. This view is reinforced by the fact that the pattern of MAP1b distribution in growing axons differs from that reported for other axonal MAPs. For example, tau protein (Dotti et al., 1987; Caceres et al., 1991) is distributed more or less uniformly along the length of growing axons. Below, we discuss these implications and also consider possible mechanisms that result in the concentration of MAPlb in the distal part of growing axons.

$\Lambda \mathrm{n}$ important clue to the manner in which MAP1b becomes concentrated in the distal region of growing axons stems from consideration of protein metabolism in the axon. The proteins of the axon are not synthesized locally therein, but are synthesized in the neuron soma and then they are conveyed into the axon by active transport mechanisms (reviewed in Lasek, 1988). While the transport rate of MAP1b in axons has not been de- termined, it is most probably conveyed with other cytoskeletal proteins by slow axonal transport. In order for MAPlb to accumulate in the distal part of growing axons, its transport rate must be, on average, faster than the average rate of axonal elongation. This creates the minimal condition necessary for MAP $1 \mathrm{~b}$ to be transported to the region of the growth cone where it can accumulate. Another important factor is the rate at which MAP $1 b$ is removed from the distal axon. For example, the rate of MAP I b proteolysis in the distal axon will influence the extent of its accumulation therein. Thus, the nonuniform distribution of MAP $1 b$ in the axon reflects a combination of the difference between the rates of MAP1b transport and axonal elongation, and the balance between the rates of its delivery and removal from different regions of the axon (see also Lasek and Katz, 1987).

The magnitude of the accumulation of MAPlb in the distal part of growing axons varied considerably within the population of neurons that we studied (see Tables 1 and 2). This may reflect the natural variation in the processes that influence the accumulation. In this regard, we note that the rate of axon elongation 
by cultured sympathetic neurons varies considerably from one neuron to another and also for individual neurons over time (Brown and Black, unpublished observations). For example, in a group of 14 neurons studied over a $3 \mathrm{hr}$ period, the average growth rates ranged from $6 \mu \mathrm{m} / \mathrm{hr}$ to $59 \mu \mathrm{m} / \mathrm{hr}$, with an overall average of $32 \mu \mathrm{m} / \mathrm{hr}$. Analyses of the rates of slow transport in axons of cultured neurons have also revealed considerable variation from one neuron to another and also at different locations within individual axons (Reinsch et al., 1991; Okabe and $\mathrm{Hi}$ rokawa, 1992). These considerations indicate that the rate of MAP1b transport relative to the rate of axon elongation may vary considerably from one neuron to another and may also vary in a single axon over time and also location. Such variations could account in part or entirely for the observed variation in the extent of MAP1b accumulation in the distal part of growing axons.

In addition to the accumulation of MAP $1 \mathrm{~b}$ in the distal region of growing axons, our data show that the MAPlb content of MTs also varies along the axon. It is relatively low and constant along the shaft, and then rises sharply in the distal axon, to reach a peak within $10-30 \mu \mathrm{m}$ of the growth cone that is, on average, 3.7 times that in the axon shaft (Fig. 5). The segmented mask procedure used to generate these data provides an average value for the relative MAPlb content for all of the MT polymer within each segment of the axon analyzed. Thus, the data reveal that the average MAPI h content of MTs varies along the axon. Highresolution images of flattened regions of the axon stained to reveal MAP1b on MTs further indicate that at any given place along the axon, there is relatively little variation in the MAPlb content of individual MTs. This is especially clear in the region of the growth cone, where individual MTs could be easily visualized by immunofluorescence procedures. All of the MTs in this region stained for MAP $1 \mathrm{~b}$, and at roughly similar intensities (Figs. 1, 4). Although the situation is less clear for the axon shaft because of the difficulty in imaging individual MTs, in the occasional flattened regions where some details of the MT array could be discerned there was no indication of substantial variation in the MAPIb content among the MI's. These considerations suggest that all of the polymer in the distal axon has a higher MAP1b content than most or all of the polymer in the axon shaft.

This regional difference in the MAPlb content of MTs may be due to the differences in the concentration of MAP1b in the distal axon compared to the axon shaft (Fig. 3). It may also reflect regional variation in MAP $1 \mathrm{~b}$ phosphorylation. In this regard, it has been reported that phosphorylation of MAPlb may enhance its assembly into MTs in vitro (Diaz-Nido et al., 1988, 1991). We have shown that MAP1b phosphorylated at the 1B-P epitope associates with MTs (Fig. 6) and that the proportion of MAPlb phosphorylated at this epitope increases progressively along the axon (Fig. 8). If this phosphorylation enhances MAPlb binding to MTs, then the progressive phosphorylation of MAPlb along the axon will also contribute to the proximal-to-distal increase in MAPIb content of MTs in the axon. The polymer of the distal axon is also enriched in tyrosinated $\alpha$-tubulin relative to that of the axon shaft (Brown et al., 1992; Ahmad et al., 1993), and it is possible that MAP1b binds more strongly to polymer rich in tyrosinated $\alpha$-tubulin. It is well documented that MAPs such as MAP2 and tau stabilize MTs (Sloboda and Rosenbaum, 1979; Job et al., 1985; Pryer et al., 1992; Umeyama et al., 1993), and a recent study has also shown that MAP1b can also stabilize MTs [when present at high
(1:1) Icvels relative to tubulin] (Takemura et al., 1992). MAPs also influence $\mathrm{MT}$ organization by affecting the packing density of neighboring MTs (Black, 1987; Chen et al., 1992). Thus, it is reasonable to expect that the regional differences in MAP1b content of MTs along the axon will result in corresponding differences in the stability and/or organization of these MTs.

In this regard, the dynamic behavior of MTs varies along the axon. This has been demonstrated by indirect assays that have compared MTs in different parts of the axon in terms of their sensitivity to the depolymerizing drug nocodazole and their relative content of tyrosinated and acetylated $\alpha$-tubulin (Baas and Black, 1990; Brown et al., 1992, 1993; Ahmad et al., 1993; Baas et al., 1993), as well as by more direct assays that have measured the time course of recovery after photobleaching of fluorescent MTs at different sites along growing axons (Lim et al., 1989; Edson et al., 1993). All of these studies indicate that, on average, the polymer of the distal axon turns over much more rapidly than the polymer of the axon shaft. The polymer of the distal axon is also more enriched in MAPlb than the polymer of the axon shaft. It is tempting to draw a connection between these observations. However, axons contain several MAPs (Black and Smith, 1988; Matus, 1988), and knowledge about the amount of these and other potential regulators of MT dynamics in different parts of growing axons is limited. Thus, it is not presently possible to dissect out the contribution of an individual MAP such as MAPlb to the overall dynamic hehavior of axonal MTs.

Nonetheless, it is significant that the polymer of the distal region of growing axons is both the more rapidly turning over polymer of these axons and the most enriched in MAP1b. Thus, the amount of MAPlb on this polymer does not preclude it from undergoing relatively rapid turnover. This is different from other MAPs, such as MAP2 and tau, which strongly suppress turnover when present at high levels on MTs (Pryer et al., 1992; Umeyama et al., 1993). Differences in the relative stabilizing activity of MAP1b compared to MAP2 and tau have also been inferred from experiments that have transfected these MAPs into cells and then examined the resulting stability of the MTs in the transfectants to nocodazole-induced depolymerization. Although all three MAPs induced drug resistance, both MAP2 and tau were much more potent than MAPlb (Takcmura et al., 1992). As nocodazole sensitivity is dependent in part on the dynamic behavior of MTs (Cassimeris et al., 1986; Kreis, 1987; Wadsworth and McGrail, 1990; Prescott et al., 1992), these observations indicate that MAP2 and tau are more efficient stabilizers of MTs than MAP1b. In this regard, it may also be relevant that the MT binding domains of MAP2 and tau are very similar to each other but very different from that of MAPIb (Noble et al., 1989). In addition, the binding affinity of MAP1b to MTs is much weaker than that of MAP2 and tau (Bloom et al., 1985). These considerations lead us to suggest that MAP1b may be specialized to permit relatively high levels of dynamics even when present at high levels on MTs.

As indicated in the introductory remarks, MAPlb is essential for axonal elongation (Brugg et al., 1993), although the precise role of MAPlb in axon growth remains to be defined. The present studies show that MAPlb is preferentially concentrated in the distal region of growing axons, and also that the MT polymer of this region is especially enriched in MAP1b compared to elsewhere in the neuron. This is a relatively unique distribution compared to the other MAPs that have been studied, which are found all along the axon and do not exhibit any enrichment in the distal axon compared to the axon shaft (Dotti 
et al., 1987; Caceres et al., 1991). The pattern of MAP1b localization in growing axons suggests that its functions in axon growth are carried out distally, in the growth cone and in the axon just behind the growth cone. This region represents one of the two major sites of MT assembly dynamics in growing axons (Brown et al., 1992). Thus, a primary function of MAP1b may be to regulate tubulin assembly dynamics in the distal axon so that it is properly coordinated with growth cone events involved in axon extension. In addition, given that MAPlb is a relatively large molecule $(\approx 320,000$ apparent molecular weight) with a relatively small MT binding domain (Noble et al., 1989), it is not unreasonable to consider the possibility that MAP1b has other functions, one or more of which may also be essential for axonal extension. Studies are in progress to inactivate MAP1b selectively in neurons actively extending axons so that we can begin to define its specific function(s) in axonal growth.

\section{References}

Ahmad FJ, Pienkowski TP, Baas PW (1993) Regional differences in microtubule dynamics in the axon. J Neurosci 13:856-866.

Aletta JM, Lewis SA, Cowan NJ, Greene LA (1988) Nerve growth factor regulates both the phosphorylation and steady state levels of microtubule-associated protein 1.2 (MAP1.2). I Cell Biol 106:15731581.

Baas PW, Black MM (1990) Individual microtubules in the axon consist of domains that differ in both composition and stability. J Cell Biol 111:495-509.

Baas PW, Ahmad FJ, Pienkowski TP, Brown A, Black MM (1993) Sites of stabilization for axonal microtubules. J Neurosci 13:21772185.

Black MM (1987) Comparison of MAP-2 and tau on the packing density of assembled microtubules. Proc Natl Acad Sci USA 84:77837787.

Black MM, Kurdyla JT (1983) Microtubule-associated proteins of neurons. J Cell Biol 97:1020-1028.

Black MM, Smith W (1988) Regional differentiation of the neuronal cytoskeleton, with an appendix: diffusion of proteins in the neuron cell body-mathematical approximations and computer simulations. In: Intrinsic determinants of neuronal form and function (Lasek RJ, Black MM, eds), pp 463-486. New York: Liss.

Black MM, Cochran JM, Kurdyla JT (1984) Solubility properties of neuronal tubulin: evidence for labile and stable microtubules. Brain Res 295:255-263.

Bloom GS, Luca FC, Vallee RB (1985) Microtubule associated protein 1B: identification of a major component of the neuronal cytoskeleton. Proc Natl Acad Sci USA 82:5404-5408.

Blose SH, Meltzer DI, Feramisco JR (1984) $10 \mathrm{~nm}$ filaments are induced to collapse in living cells microinjected with monoclonal and polyclonal antibodies against tubulin. J Cell Biol 98:847-858.

Boyne L, Sagot Y, Tessler A, Fischer I (1992) Expression of MAPIb and tau during regeneration of newborn and adult rat DRG in culture. Soc Neurosci Abstr 18:186.3.

Brown A, Slaughter T, Black MM (1992) Newly assembled microtubules are concentrated in the proximal and distal regions of growing axons. J Cell Biol 1 19:867-882.

Brown A, Slaughter T, Black MM (1993) Composite microtubules of the axon: quantitative analysis of tyrosinated and acetylated $\alpha$-tubulin along axonal microtubules. J Cell Sci 104:339-352.

Brugg B, Matus A (1988) PC12 cells express juvenile microtubule associated proteins during nerve growth factor-induced neurite outgrowth. J Cell Biol 107:643-650.

Brugg B, Reddy D, Matus A (1993) Attenuation of microtubule associated protein $1 \mathrm{~B}$ expression by antisense oligonucleotides inhibits initiation of neurite outgrowth. Neuroscience 52:489-496.

Caceres A, Potrebic S, Kosik KS (1991) The effect of tau antisense oligonucleotides on neurite formation of cultured cerebellar macroneurons. J Neurosci 11:1515-1523.

Calvert R, Anderton BH (1985) A microtubule-associated protein (MAP1) which is expressed at elevated levels during development of the rat cerebellum. EMBO J 4:1171-1176.
Calvert R, Woodhams PL, Anderton BH (1987) Localization of an epitope of a microtubule-associated protein $1 \mathrm{x}$ in outgrowing axons of the developing rat central nervous system. Neuroscience 23:131141 .

Cassimeris LU, Wadsworth P, Salmon ED (1986) Dynamics of microtubule depolymerization in monocytes. J Cell Biol 102:2023-2032.

Chen J, Kanai Y, Cowan NJ, Hirokawa N (1992) Projection domains of MAP2 and tau determine spacings between microtubules in axons and dendrites. Nature 360:674-677.

Diaz-Nido J, Serrano L, Mendez E, Avila J (1988) A casein kinase II related activity is involved in phosphorylation of microtubule-associated protein MAP-1B during neuroblastoma cell differentiation. J Cell Biol 106:2057-2065.

Diaz-Nido J, Armas-Portela R, Correas I, Dominguez JE, Montejo E, Avila J (1991) Microtubule protein phosphorylation in neuroblastoma cells and neurite growth. J Cell Sci [Suppl] 15:51-59.

Dotti CG, Banker GA, Binder LI (1987) The expression and the distribution of the microtubule-associated proteins tau and microtubule associated protein 2 in hippocampal neurons in the rat in situ and in cell culture. Neuroscience 23:121-130.

Drubin DG, Feinstein SC, Shooter EM, Kirschner MW (1985) Nerve growth factor induced outgrowth in PC12 cells involves the coordinate induction of microtubule assembly and assembly promoting factors. J Cell Biol 101:1799-1807.

Edson KJ, Lim S-S, Borisy GG, Letourneau PC (1993) FRAP analysis of the stability of the microtubule population along the neurites of chick sensory neurons. Cell Motil Cytoskel 25:59-72.

Fischer I, Romano-Clarke G (1990) Changes in microtubule-associated protein MAPIb phosphorylation during rat brain development. J Neurochem 55:328-333.

Fischer I, Romano-Clarke G (1991) Association of microtubule associated protein (MAP1B) with growing axons in cultured hippocampal neurons. Mol Cell Neurosci 2:39-51.

Garner CC, Garner A, Huber G, Kozak C, Matus A (1990) Molecular cloning of microtubule-associated proteins 1 (MAP1A) and microtubule associated protein 5 (MAP1B): identification of distinct genes and their differential expression in developing brain. J Neurochem 55:146-154.

Gordon-Weeks PR (1991) Control of microtubule assembly in growth cones. J Cell Sci [Suppl] 15:45-49.

Greene LA, Liem RKH, Shelanski ML (1983) Regulation of a high molecular weight microtubule-associated protein in PC12 cells by nerve growth factor. J Cell Biol 96:76-83.

Job D, Pabion M, Margolis RM (1985) Generation of microtubule stability subclasses by microtubule-associated proteins: implications for the microtubule "dynamic instability" model. J Cell Biol 101: $1680-1689$

Kreis T (1987) Microtubules containing detyrosinated tubulin are less dynamic. EMBO J 6:2597-2606.

Lasek RJ (1988) Studying the intrinsic determinants of neuronal form and function. In: Intrinsic determinants of neuronal form and function (Lasek RJ, Black MM, eds), pp 3-58. New York: Liss.

Lasek RJ, Katz MJ (1987) Mechanisms at the axon tip regulate metabolic processes critical to axonal elongation. Prog Brain Res 71:4960.

Lim S-S, Sammak PJ, Borisy GG (1989) Progressive and spatially differentiated stability of microtubules in developing neuronal cells. J Cell Biol 109:253-263.

Mansfield SG, Diaz-Nido J, Gordon-Weeks PR, Avila J (1992) The distribution and phosphorylation of the microtubule-associated proteins MAPlb in growth cones. J Neurocytol 21:1007-1022.

Matus A (1988) Microtubule-associated proteins: their potential role in determining neuronal morphology. Annu Rev Neurosci 11:29-44.

Noble M, Lewis SA, Cowan NJ (1989) The microtubule-binding domain of microtubule-associated protein MAPIB contains a repeated sequence motif unrelated to that of MAP2 and tau. J Cell Biol 109: 3367-3376.

Nothias F, Murray M, Tessler A, Fischer I (1992) Expression and distribution of microtubule associated proteins in DRG neurons after sciatic nerve lesion in adult rats. Soc Neurosci Abstr 18:186.2.

Okabe S, Hirokawa N (1992) Differential behavior of photoactivated microtubules in growing axons of mouse and frog neurons $J$ Cell Biol 117:105-120.

Peng I, Binder LI, Black MM (1985) Cultured neurons contain a variety of microtubule-associated proteins. Brain Res 361:200-211.

Peng I, Binder LI, Black MM (1986) Biochemical and immunochem- 
ical analyses of cytoskeletal domains of neurons. J Cell Biol 102:252262.

Prescott AR, Dowrick PG, Warn RM (1992) Stable and slow turning over microtubules characterize the processes of motile epithelial cells treated with scatter factor. J Cell Sci 102:103-112.

Pryer NK, Walker RA, Skeen VP, Bourns BD, Soboeiro MF, Salmon ED (1992) Brain microtubule-associated proteins modulate microtubule dynamic instability in vitro. Real-time observations using video microscopy. J Cell Sci 103:965-976.

Reinsch SS, Mitchison TJ, Kirschner MW (1991) Microtubule polymer assembly and transport during axonal elongation. J Cell Biol 115 : 365-379.

Riederer BM, Cohen R, Matus A (1986) MAP5: a novel brain microtubule-associated protein under strong developmental regulation. J Neurocytol 15:763-775.

Riederer BM, Guadano-Ferraz A, Innocenti GM (1990) DIfference in distribution of microtubule-associated proteins $5 \mathrm{a}$ and $5 \mathrm{~b}$ during the development of cerebral cortex and corpus callosum in cats: dependence on phosphorylation. Dev Brain Res 56:235-243.

Safaei R, Fischer I (1989) Cloning of a cDNA encoding MAPlb in rat brain; regulation of mRNA levels during development. $J$ Neurochem 52:1871-1879.

Sato-Yoshitake R, Shiomura Y, Miyasaka H, Hirokawa N (1989) Microtubule-associated protein $\mathrm{B}$ : molecular structure, localization, and phosphorylation-dependent expression in developing neurons. Neuron 3:229m238.

Schliwa M, van Blerkom JJ (1981) Structural interactions of cytoskeletal components. J Cell Biol 90:222-235.

Sloboda RD, Rosenbaum JL (1979) Decoration and stabilization of intact, smooth-walled microtubules with microtubule-associated proteins. Biochemistry 18:48-55.

Takemura R, Okabe S, Umeyama T, Kanai Y, Cowan NJ, Hirokawa $N$ (1992) Increased microtubule stability and alpha-tubulin acetylation in cells transfected with microtubule-associated proteins MAP1B, MAP2 or tau. J Cell Sci 103:953-964.

Tucker RP (1990) The role of microtubule-associated proteins in brain morphogenesis: a review. Brain Res Rev 15:109-120.

Umeyama T, Okabe S, Kanai Y, Hirokawa N (1993) Dynamics of microtubules bundled by microtubule-associated protein $2 \mathrm{C}$ (MAP2C). J Cell Biol 120:451-465.

Vallee RB (1982) A taxol-dependent procedure for the isolation of microtubules and microtubule-associated proteins (MAPs). J Cell Biol 92:435-442.

Viereck C, Tucker RP, Matus A (1989) The adult rat olfactory system expresses microtubule-associated proteins found in the developing brain. J Neurosci 9:3547-3557.

Wadsworth P, McGrail M (1990) Interphase microtubule dynamics are cell type-specific. J Cell Sci 95:23-32. 